\title{
Treatment of Abdominal Wall Endometriosis Using a Mini-Abdominoplasty Design
}

\author{
Kyunghyun Min, Hyun Ho Han \\ Department of Plastic Surgery, Asan \\ Medical Center, University of Ulsan \\ College of Medicine, Seoul, Korea
}

No potential conflict of interest relevant to this article was reported.

\begin{abstract}
Abdominal wall endometriosis is a condition in which functioning endometrial tissue is present outside the uterine cavity, and the standard treatment is extensive surgical excision. A 46-year-old woman presented with an irregular lower abdominal mass measuring $8.5 \times 4.5 \mathrm{~cm}$. The patient had a history of a cesarean delivery 15 years previously. For treatment, a mini-abdominoplasty was designed to avoid possible wound complications and to optimize the cosmetic outcomes. The lesion was excised with an adequate margin because of the possibility of recurrence. The resected structures were the lower mid-abdominal skin, subcutaneous fat, anterior and posterior rectus sheath, and rectus abdominis muscle. The incisional wound was closed layer by layer, including abdominal fascia repair with acellular dermal matrix. At a 3-month postoperative outpatient follow-up visit, the patient was highly satisfied with the cosmetic results and reported no complications. Optimal oncological, functional, and cosmetic surgical outcomes can be achieved by complete excision followed by mini-abdominoplasty.
\end{abstract}

Keywords Abdominal wall, Abdominoplasty, Endometriosis

\section{INTRODUCTION}

Endometriosis is a common gynecological disease involving the ectopic growth of endometrial tissue [1]. Endometriosis found on abdominal incisions is referred to as abdominal wall endometriosis (AWE) [2]. The prevalence of AWE has been estimated to range from $0.04 \%$ to $12.3 \%$ [3]. Many cases of AWE are associated with cesarean section scars, and laparoscopic port sites, hernia repairs, and laparotomies can also induce AWE [4]. Thus, AWE is often misdiagnosed as a hernia, hematoma, or lipoma, resulting in a surgical consultation.

The most appropriate treatment of AWE is surgical management with a margin of at least $1 \mathrm{~cm}$. In contrast, medical manage-

\footnotetext{
Received: Apr 26, 2018 Revised: May 31, 2018 Accepted: May 31, 2018 Correspondence: Hyun Ho Han Department of Plastic Surgery, Asan Medical Center, University of Ulsan College of Medicine, 88 Olympic-ro 43-gil, Songpa-gu, Seoul 05505, Korea.

E-mail: tripleh1952@gmail.com
}

Copyright @ 2018 The Korean Society for Aesthetic Plastic Surgery.

This is an Open Access article distributed under the terms of the Creative Commons Attribution Non-Commercial License (http://creativecommons.org/licenses/by-nc/4.0/) which permits unrestricted non-commercial use, distribution, and reproduction in any medium, provided the original work is properly cited. www.e-aaps.org ment of AWE has shown low levels of success [5]. Preliminary studies evaluating therapeutic percutaneous cryoablation have shown promise, with a decrease in lesion volume [6]. However, some reports of clear cell adenocarcinoma associated with AWE have been reported, underscoring the need for wide surgical excision.

In cases of large abdominal endometriosis, excision of the mass and direct closure can result in a conspicuously asymmetric abdominal contour. Moreover, the large size of the tumor to be removed makes it challenging for surgeons to reconstruct the abdominal wall. Since Kelly [7] first reported the use of a large horizontal mid-abdominal incision to correct excessive abdominal tissue, many abdominoplasty techniques have been developed. Some surgeons have performed a mini-abdominoplasty with mesh to cover AWE defects, with good cosmetic and surgical outcomes $[8,9]$. In this case study, we present a case of abdominal wall reconstruction using a mini-abdominoplasty design after wide excision of a large AWE.

\section{CASE REPORT}

A 46-year-old woman presented with a palpable mass on the lower mid-abdomen without tenderness. She had undergone a cesarean delivery 15 years ago and suffered from an infection. On physical 
examination, a lower abdominal mass was palpated at the mid-abdomen (Fig. 1). It was non-tender, irregular, and fixed to the deep tissue. On abdominopelvic computed tomography, an irregular heterogeneous enhancing lesion measuring roughly $8.5 \times 4.5 \mathrm{~cm}$ was observed at the lower rectus abdominis muscle (Fig. 2). It adhered to the subcutaneous tissue and deep fascia, and ultrasonography-guided needle biopsy confirmed that the lesion was endometriosis. The gynecologic surgery team at our institution decided

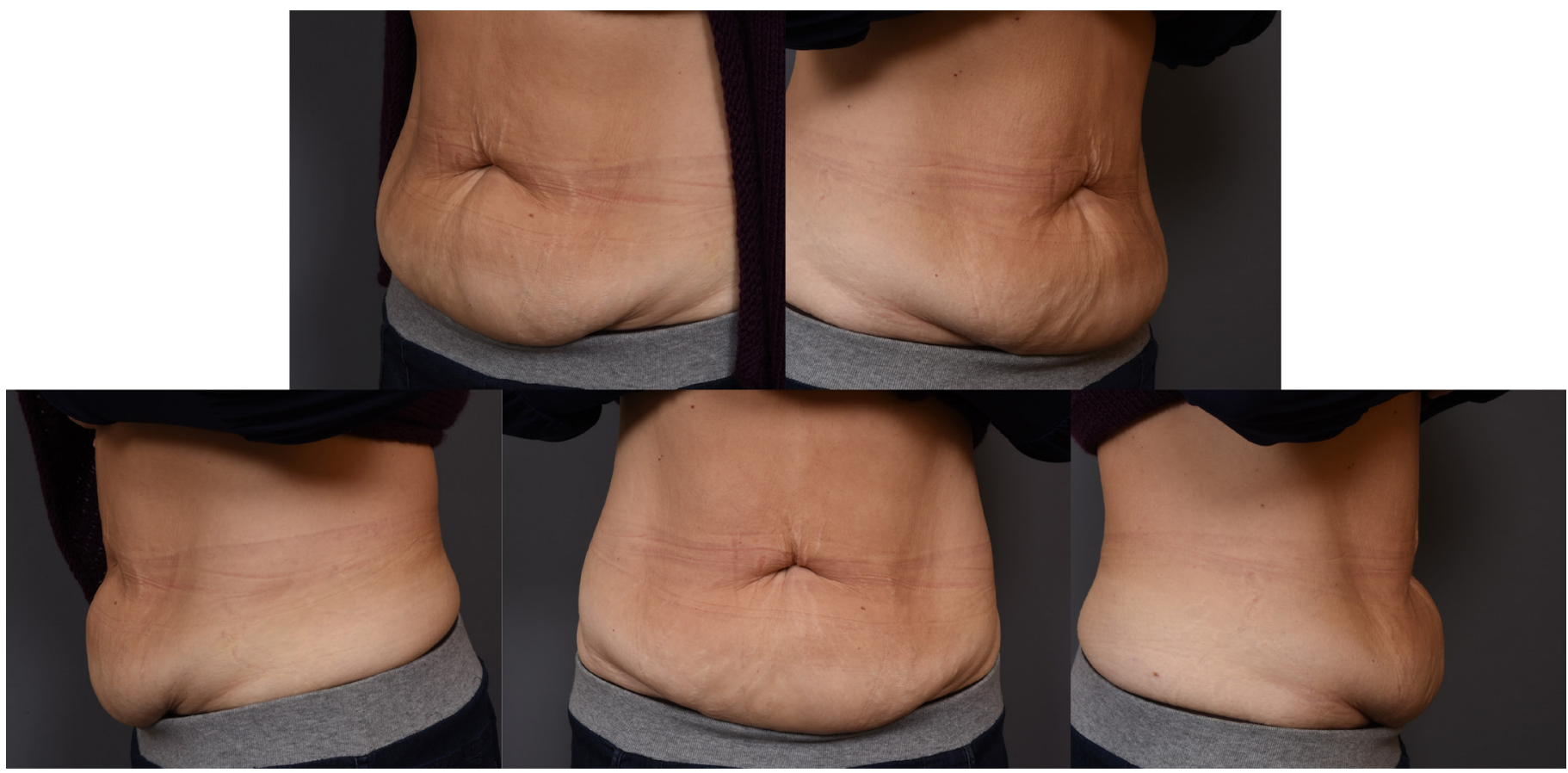

Fig. 1. Preoperative photograph showing lower abdominal bulging with a palpable mass. Mild skin laxity was observed.

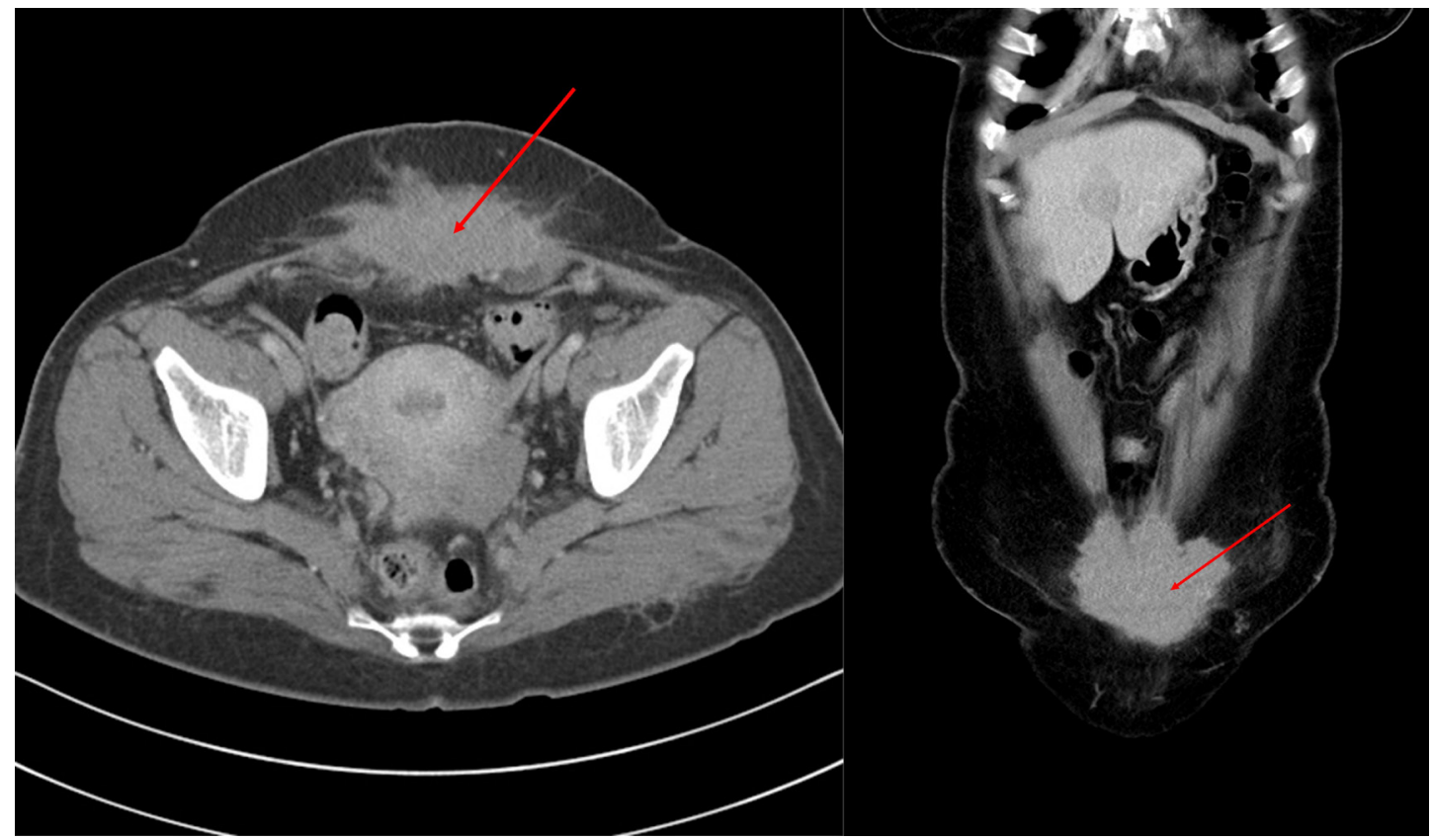

Fig. 2. Preoperative abdominopelvic computed tomography. An irregular heterogeneous enhancing lesion measuring $8.5 \times 4.5 \mathrm{~cm}$ was observed at the lower rectus abdominis muscle (red arrow). It adhered to the subcutaneous tissue and deep fascia. Incisional biopsy reported endometriosis. 
to remove the mass.

Under general anesthesia, skin incision and dissection around the mass was followed by a mini-abdominoplasty design, including

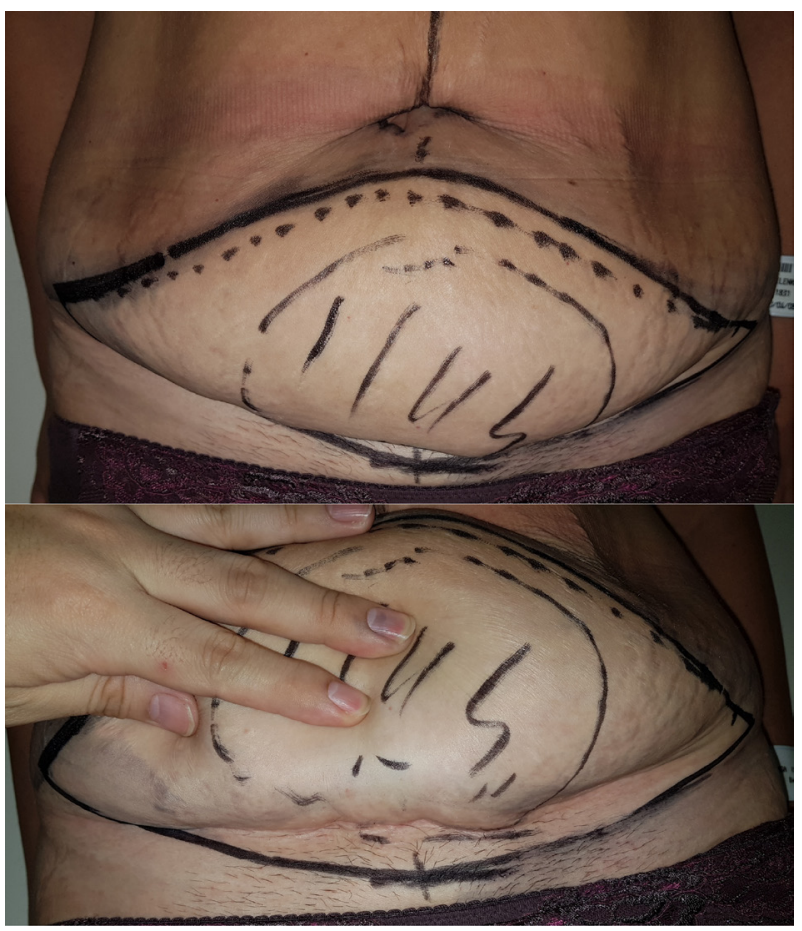

the cesarean section scar (Fig. 3). Endometrial tissue was found penetrating not only the rectus abdominis, but also the posterior sheath of the rectus muscle. Moreover, there was a high suspicion of bladder involvement. Therefore, the gynecologic team made a peritoneal incision at the superior area of the bladder to identify the extent of endometriosis. Fortunately, the urinary bladder was intact. The final excised mass measured $10.0 \times 9.1 \times 3.7 \mathrm{~cm}$, including the anterior abdominal. Peritoneal layer repair was performed with Vicryl 1-0 (Ethicon Inc., Somerville, NJ, USA) after meticulous hemostasis.

The plastic surgery team joined the operation afterward. The anterior rectus sheath was not closed primarily, so a piece of acellular dermal matrix measuring $5 \times 4 \mathrm{~cm}$ (MegaDerm; L\&C Bio Corp., Seongnam, Korea) was used for fascia repair with a defect that was $8 \times 5 \mathrm{~cm}$ in size. Umbilicus repositioning was not performed, the Scarpa fascia layer was repaired with Vicryl 1-0, and the dermal layer was repaired with polydioxanone II 3-0 and 4-0 sutures (Ethicon Inc.). The skin layer was closed using Dermabond Prineo ${ }^{\circledR}$ (Ethicon Inc.). All drains were removed 11 days after surgery. The patient kept a bandage on the abdomen for a month. At a 3-month postoperative outpatient follow-up visit, her scar had healed well, and it was hidden when she wore underwear. No postoperative complications, such as abdominal hernia, seroma formation, surgical site infection, or wound dehiscence, were observed. The patient was highly satisfied with the results (Fig. 4).

Fig. 3. Preoperative design. The lesion did not involve the umbilicus, so a mini-abdominoplasty design was planned, including the previous cesarean section scar.

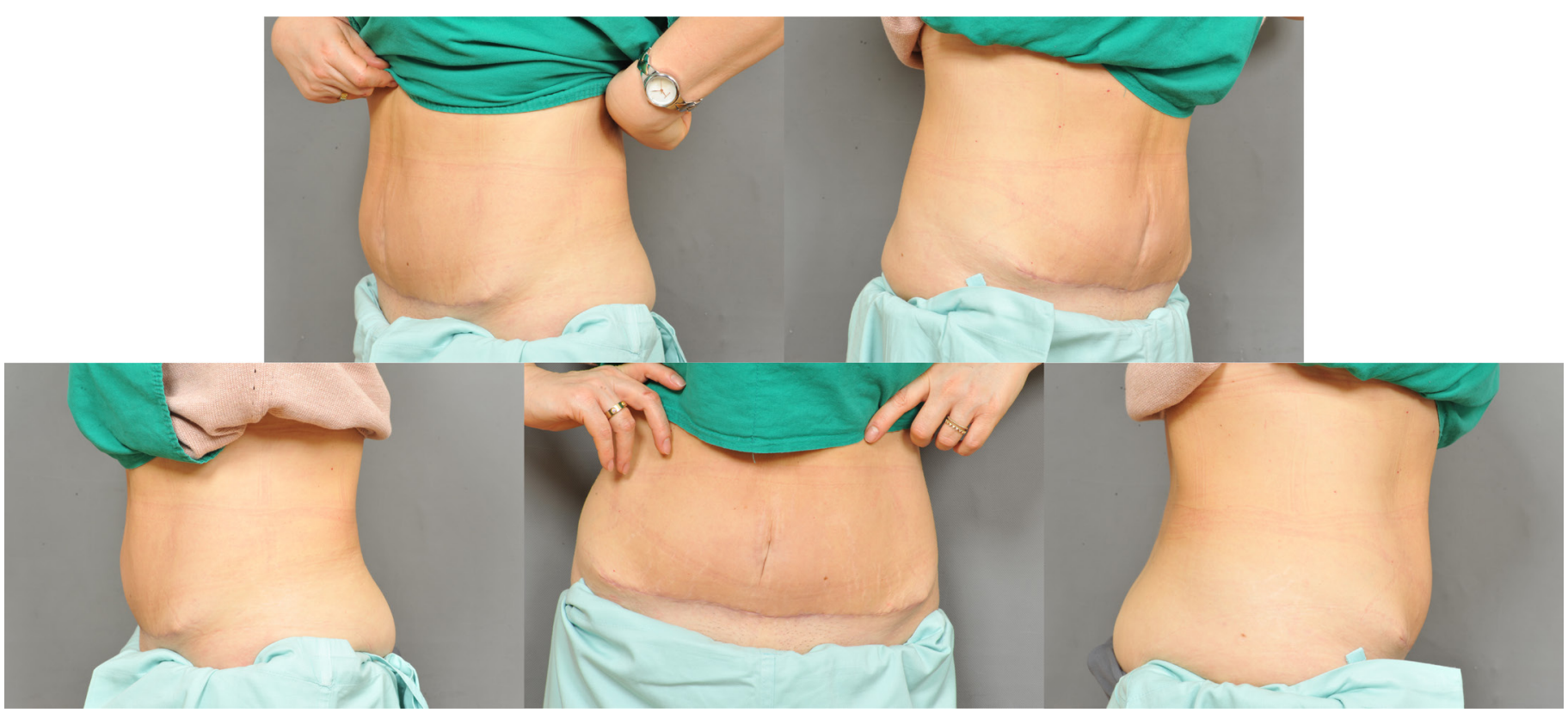

Fig. 4. Photograph from 3 months postoperatively. The wound had completely recovered without scar widening, recurrence, or complications such as hematoma, abdominal hernia, or wound dehiscence. 


\section{DISCUSSION}

AWE tends to recur, so the lesion should be resected with an adequate ablation margin. Based on the size and depth of the mass, the method of wound closure varies, so a detailed intraoperative wound assessment should be performed. Patel et al. [10] described a component separation technique with a medial advancement of 3 to 5 $\mathrm{cm}$ in the epigastrium, 7 to $10 \mathrm{~cm}$ at the umbilical area, and 1 to 3 $\mathrm{cm}$ in the suprapubic area for a single side, with double these figures for a bilateral component separation. If the fascia is not closed primarily, or is closed with severe tension, synthetic/biological mesh can also be considered.

In this case, AWE did not spread widely to the skin. Moreover, the abdominal skin has mild laxity, so wound closure was possible even though an extensive amount of tissue was removed. Therefore, the mini-abdominoplasty design was possible because skin closure was easy. Additionally, the umbilicus had not been invaded and did not need to be repositioned. If a lesion invades the umbilical area or the abdominal tissue below the umbilicus, a classic abdominoplasty design is needed [11]. If a neo-umbilicus must be made or umbilical repositioning is needed, a simple method is to place the position of the umbilicus at the highest level of the iliac crest [12]. Furthermore, the ratio between the umbilicus-xiphoid process and umbilicus-symphysis pubis (1.6:1) can be used to determine the umbilicus location [13].

For plastic surgeons, abdominoplasty is a basic concept, but it may be an unfamiliar procedure for gynecologists. Sharing of surgical information between these departments is important, and the excision planning of the gynecologic surgery and the design of the plastic surgeon are accordingly important. Collaborative treatments of AWE, which may result in cosmetic issues, can lead to more satisfactory results for the patient.

\section{PATIENT CONSENT}

The patient provided written consent for the use of her images.

\section{REFERENCES}

1. Horton JD, Dezee KJ, Ahnfeldt EP, et al. Abdominal wall endometriosis: a surgeon's perspective and review of 445 cases. Am J Surg 2008; 196:207-12.

2. Ecker AM, Donnellan NM, Shepherd JP, et al. Abdominal wall endometriosis: 12 years of experience at a large academic institution. Am J Obstet Gynecol 2014;211:363.e1-5.

3. Zhao X, Lang J, Leng J, et al. Abdominal wall endometriomas. Int J Gynaecol Obstet 2005;90:218-22.

4. Blanco RG, Parithivel VS, Shah AK, et al. Abdominal wall endometriomas. Am J Surg 2003;185:596-8.

5. Chatterjee SK. Scar endometriosis: a clinicopathologic study of 17 cases. Obstet Gynecol 1980;56:81-4.

6. Cornelis F, Petitpierre F, Lasserre AS, et al. Percutaneous cryoablation of symptomatic abdominal scar endometrioma: initial reports. Cardiovasc Intervent Radiol 2014;37:1575-9.

7. Kelly HA. Excision of fat of the abdominal wall lipectomy. Surg Gynecol Obstet 1910;10:229-31.

8. Lee ET, Park HM, Lee DG, et al. Application of mini-abdominoplasty after conservative excision of extensive cesarean scar endometriosis. Arch Plast Surg 2012;39:551-5.

9. Zhao R, Wang XJ, Song KX, et al. Mini-abdominoplasty combined with mesh used for abdominal wall endometriosis. Chin Med J (Engl) 2012;125:1614-7.

10. Patel NG, Ratanshi I, Buchel EW. The best of abdominal wall reconstruction. Plast Reconstr Surg 2018;141:113e-36e.

11. Matarasso A, Matarasso DM, Matarasso EJ. Abdominoplasty: classic principles and technique. Clin Plast Surg 2014;41:655-72.

12. Dubou R, Ousterhout DK. Placement of the umbilicus in an abdominoplasty. Plast Reconstr Surg 1978;61:291-3.

13. Duduković M, Kisić $\mathrm{H}$, Baez ML, et al. Anatomical prediction for surgical positioning of the umbilicus in a Croatian population. Ann Plast Surg 2015;75:135-9. 